\title{
Educação empreendedora no ensino de Administração: a simulação realística como instrumento didático
}

\author{
Entrepreneurial education in Administration teaching: a realistic simulation as a teaching \\ instrument
}

La formación emprendedora en la Administración docente: la simulación realista como instrumento docente

\author{
Cristiano Valério Ribeiro \\ ORCID: https://orcid.org/0000-0003-2202-5498 \\ Centro Universitário Unifaminas, Brasil \\ E-mail: cristianovribeiro@gmail.com \\ Alan Ferreira de Freitas \\ ORCID: https://orcid.org/0000-0002-5952-2546 \\ Universidade Federal de Viçosa, Brasil \\ E-mail: alanf.freitas@ufv.br \\ Samuel Soares da Silva \\ ORCID: https://orcid.org/0000-0002-5278-7779 \\ Universidade Federal de Viçosa, Brasil \\ E-mail: samuelsoaresadm@gmail.com
}

\begin{abstract}
Resumo
O trabalho analisou de maneira inovadora a aplicação da metodologia de Simulação Realística (SR) como estratégia didático-pedagógica da prática de educação empreendedora no ensino da ciência da administração. A justificativa se baseia na constatação que a metodologia de ensino predominante nos cursos de Administração é tradicionalmente conteudista e pouco estimula a criatividade e manifestações empreendedoras de forma prática. A pesquisa que subsidiou a realização deste trabalho pode ser caracterizada como de abordagem qualitativa, desenvolvido segundo o método de estudo de caso único, tendo por base a adoção da metodologia de Simulação Realística seguido de entrevistas semiestruturadas realizadas no campus da Universidade Federal de Viçosa. O universo estudado foi composto por dois grupos, um com estudantes de graduação e outro com estudantes do programa de mestrado, ambos em Administração da UFV. Os principais achados demonstram que a SR é um importante instrumento da prática docente capaz de contribuir de forma inovadora no processo de educação empreendedora nos cursos de administração. Portanto, conclui-se que houve êxito na experiência crítico-reflexiva da utilização de uma metodologia ativa como estratégia didático-pedagógica no processo de educação empreendedora no ensino da administração.
\end{abstract}

Palavras-chave: Educação empreendedora; Metodologias ativas; Simulação realística; Inovação.

\begin{abstract}
The work analyzed the application of the Realistic Simulation (SR) methodology inovation as a didactic-pedagogical strategy for the practice of entrepreneurial education in business administration. The justification is based on the observation that the teaching methodology prevalent in Business Administration courses is traditionally contentious and does not stimulate creativity and entrepreneurial manifestations in a practical way. The research that supported the realization of this work can be characterized as a qualitative approach, developed according to the method of a single case study, based on the adoption of the Realistic Simulation methodology followed by semi-structured interviews carried out on the campus of the Federal University of Viçosa. The studied universe was composed of two groups, one with undergraduate students and the other with students from the master's program, both in UFV Administration. The main findings demonstrate that SR can be an important instrument of teaching practice capable of increasing resources used in entrepreneurial education processes in administration courses. Therefore, it is concluded that there was success in the critical-reflexive experience of active methodology as a didactic strategy in the entrepreneurial education process.
\end{abstract}

Keywords: Entrepreneurial education; Active methodologies; Realistic simulation; Innovation.

\section{Resumen}

El trabajo analizó de manera innovadora la aplicación de la metodología de Simulación Realista (SR) como estrategia didáctico-pedagógica para la práctica de la educación emprendedora en la enseñanza de las ciencias de la gestión. La 
justificación se basa en la observación de que la metodología de enseñanza predominante en los cursos de Administración de Empresas es tradicionalmente polémica y no estimula la creatividad y las manifestaciones emprendedoras de forma práctica. La investigación que apoyó la realización de este trabajo se puede caracterizar como un abordaje cualitativo, desarrollado según el método de un estudio de caso único, basado en la adopción de la metodología de Simulación Realista seguida de entrevistas semiestructuradas realizadas en el campus de la Universidad Federal de Viçosa. El universo estudiado estuvo compuesto por dos grupos, uno con estudiantes de pregrado y otro con estudiantes de la maestría, ambos en Administración de la UFV. Los principales hallazgos demuestran que la RS es un importante instrumento de práctica docente capaz de contribuir de manera innovadora al proceso de formación emprendedora en los cursos de administración. Por tanto, se concluye que hubo éxito en la experiencia crítico-reflexiva de utilizar una metodología activa como estrategia didáctico-pedagógica en el proceso de educación empresarial en la enseñanza de la administración.

Palabras clave: Educación emprendedora; Metodologías activas; Simulación realista; Innovación.

\section{Introdução}

A capacidade para lidar e agir com as transformações do século XXI se tornou, também, um desafio para os administradores, pois estas novas demandas permeiam o campo do conhecimento das competências ao invés de estar estritamente relacionado ao perfil técnico convencional do administrador, o que implica um novo modo de ensinoaprendizagem que evidência a emancipação, capacidade inovadora e crítico-reflexiva dos envolvidos, tais características encontradas no processo de educação empreendedora (Barcellos, Dellagnelo \& Saliés, 2011).

Neste sentido, do ponto de vista da aprendizagem, a importância dos estudos de Vygotsky é inquestionável, pois ele critica as teorias que separam a aprendizagem do desenvolvimento ao afirmar que entendia que a aprendizagem não era uma mera aquisição de informações, não acontecia a partir de uma simples associação de ideias armazenadas na memória, mas era um processo interno, ativo e interpessoal (Carvalho, 2016).

$\mathrm{Na}$ abordagem vygotskyana, o homem é visto como alguém que transforma e é transformado nas relações que acontecem em uma determinada cultura. O que ocorre não é uma somatória entre fatores inatos e adquiridos e sim uma interação dialética que se dá, desde o nascimento, entre o ser humano e o meio social e cultural em que se insere. Assim, é possível constatar que do ponto de vista de Vygotsky o desenvolvimento humano é compreendido não como a decorrência de fatores isolados que amadurecem, nem tampouco de fatores ambientais que agem sobre o organismo controlando seu comportamento, mas sim como produto de trocas recíprocas, que se estabelecem durante toda a vida, entre indivíduo e meio, cada aspecto influindo sobre o outro (Silva \& Torres, 2017).

Ressalta-se que o conceito de educação evoluiu, ultrapassando as fronteiras de espaço e tempo em que o aluno faz o seu período de escolarização, para dar lugar a um processo de aprendizagem ao longo da vida, isto é, possibilitando a cada um a capacidade de saber conduzir a sua vida num mundo onde a rapidez das mudanças se alia ao fenômeno da globalização, e no qual requer um alto grau de competitividade que, mais do que nunca necessita da busca pela educação empreendedora (Penaluna, 2018).

O relatório The Future of Jobs (WEF, 2016) aponta as tendências das demandas dos empregadores mundiais referente às habilidades esperadas dos futuros candidatos às vagas em suas empresas. Foi identificado dez habilidades mais valorizadas por estes profissionais diante da complexidade do século XXI e ao avanço da economia digital: resolução de problemas, capacidade crítica, criatividade, capacidade de gerenciar e influenciar pessoas, inteligência emocional, tomada de decisão, orientação para o serviço, negociação e flexibilidade. Todavia, a pesquisa sugere que o desenvolvimento de habilidade sociais e emocionais devem ser prioridades para administradores, empreendedores, organizações e mercado de trabalho (Godoi \& Ferreira, 2016).

Sob tal perspectiva, Dalfovo et al., (2017), demonstra que o conjunto dos sujeitos em situação profissional, independente de cargo, possui capacidades intrínsecas de ação e transformação de seu ambiente organizacional. São sujeitos 
biopsicossociais que vivenciam prazer, sofrem, adoecem. São, igualmente, carregados de desejos, ambições e sonhos, dotados ainda da necessidade de reconhecimento, cujo sistema psíquico de maneira consciente e muitas vezes inconsciente influencia suas respectivas condutas. Outro pressuposto importante é que a vida coletiva os mobilizam na constituição de identidades profissionais que mais uma vez impactam o meio de trabalho e as organizações (Meyer \& Jongh, 2018).

Assim sendo, à medida que se reconhece a necessidade de se desenvolver habilidades sociais e emocionais, e não apenas prover conhecimentos, a criação de ambientes para a mediação das relações indivíduo-trabalho-organização podem implicar em importantes resultados para o desenvolvimento empreendedor, saudável e sustentável da sociedade. Neste caso, ir além do modelo de educação tradicional e formal onde o aluno a sala a aula e processo de ensino-aprendizagem é centrada na autoridade do professor e não na curiosidade e protagonismo do aluno é crucial (Deveci \& Çepni, 2017).

Nessa direção, a Simulação Realística (SR) ou simulação de alta fidelidade emerge como uma importante possibilidade de alavancar ambientes de aprendizado mais aderentes à dinâmica contemporânea e às necessidades de ressignificação da sala de aula. De acordo com Gaba (2007), a simulação realística pode ser entendida como o processo que replica cenários em um ambiente próximo a realidade, com o objetivo de analisar e refletir as ações realizadas de forma segura. A simulação é, sobretudo, uma técnica, e não exclusivamente uma tecnologia, que tem por objetivo amplificar uma experiência real com supervisão, que evoca substancialmente aspectos do mundo real em um ambiente interativo (Gaba, 2007).

Desse modo, a simulação realística é uma ferramenta que pode ser aplicada em todos os níveis da organização ou nos processos de ensinoalrendizagem, enfatizando a multidisciplinaridade em diversas situações cotidianas. Especialmente em simulações comportamentais de alta fidelidade e alta complexidade, em que é possível a reflexão sobre as ações realizadas pelos envolvidos com o auxílio de um facilitador que acompanhou o cenário simulado (Charity et. al., 2017). Esse, por sua vez, deve assumir postura de mediar a discussão em grupo sobre o sentido das ações, os acertos e as oportunidades de melhorias. Também no campo das organizações, a aplicação da metodologia demonstra que sujeitos cujas condutas revelam maior capacidade para admitir a incerteza, o conflito e a contradição se mostram mais aptos a lidar com situações mais complexas (Clayton et. al., 2017).

Visando, portanto, investigar a aplicação da metodologia SR como forma de fomentar o processo de educação empreendedora na formação de administradores, o presente artigo tem como propósito central analisar implicações da simulação realística na formação de graduandos e mestrandos do curso de administração da Universidade Federal de Viçosa (UFV), face às demandas decorrentes do mercado atual de trabalho em que se inserem. Especificamente foi possível: Averiguar o papel da SR em propiciar respostas às transformações que caracterizam o mercado de trabalho em que se inserem os profissionais alvo da pesquisa; Analisar em que extensão a SR se apresenta capaz de desenvolver as competências requeridas, sob a perspectiva dos indivíduos pesquisados; Identificar implicações da SR na construção de vantagens profissionais competitivas; Analisar diferenças e semelhanças quanto à percepção da SR no desenvolvimento das competências requeridas pelos profissionais de administração. Assim sendo, a questão central que orientou a realização deste estudo pode ser assim sintetizada: De que forma a SR enquanto metodologia ativa contribui para inovar e instrumentalizar processos educativos em cursos de Administração?

Este artigo está organizado em quatro sessões além dessa introdução. A próxima sessão aborda elementos conceituais inerentes a necessidade analítica e argumentativa levantada pela pesquisa refletindo sobre as implicações do método de SR como fonte provedora de educação empreendedora no ensino de administração. Posteriormente são apresentadas as estratégias metodológicas empregadas e em seguida os resultados e discussão, especificando alguns importantes achados da pesquisa. Por fim, são elencadas as conclusões. 


\section{Educação de Adultos: uma Reflexão à Luz da Andragogia}

Os crescentes avanços tecnológicos e científicos, conforme relatam Silva e Torres (2017), impõem ao profissional do século XXI necessidades específicas que diferem consideravelmente dos objetivos da educação básica, mais centrada em conteúdos introdutórios, e que segue padrões pedagógicos direcionados pelos professores. Ademais, a condição de adulto geralmente leva o educando a ter níveis de interesse e comprometimento que dependem de práticas pedagógicas mais ajustadas à sua maturidade, necessidades profissionais e exigências pessoais. Isso ocorre principalmente nos cursos de graduação, pósgraduação e educação ou formação continuada (Bolzan, 2017).

A reflexão sobre o ensino nas universidades é uma tarefa urgente, posto que o Ensino Superior voltado às tecnologias, licenciaturas ou bacharelados, se apresenta como um processo sempre inacabado, no qual tempos, disciplinas, conteúdos e didáticas estão fundamentados, geralmente, em uma perspectiva de ensino tradicionalista, conteudista e enciclopedista (Carvalho, 2016).

Decorre então, uma nova perspectiva: a andragogia, a maneira de aprender dos adultos, estabelecendo-se novas formas metodológicas de ensino e aprendizagem. A teoria andragógica traz novas perspectivas sobre a aprendizagem, lança desafios ao professor universitário e se apresenta como uma ciência que tem como objetivo facilitar a aprendizagem dos adultos e possibilitar que o professor promova a "[...] educabilidade, ou seja, favorecer para que os sujeitos, eles próprios, tornem-se construtores e transformadores de sua individualidade, da subjetividade e da própria sociedade (Romanowski, 2007, p. 115).

Os princípios do modelo andragógico demonstra que após o desenvolvimento infantil, o ser humano, durante a vida adulta atravessa ainda um processo de desenvolvimento físico e psicológico relacionado com o seu status e com as suas responsabilidades sociais perante terceiros, bem como com o seu maior reservatório de experiências, o que torna mais particulares as suas necessidades de aprendizagem (Carvalho, 2016). Assim, é preciso considerar que a aprendizagem nos adultos é diferente em extensão e na forma, comparativamente à aprendizagem nas crianças.

De modo geral, é possível registrar que a andragogia e a pedagogia apresentam diferenças bastante significativas em sua forma de abordar o aprendiz, nas metodologias empregadas pelo professor para que ocorra a aprendizagem, bem como na maneira de motivar o aluno (Silva \& Torres, 2017). As diferenças básicas entre os dois modelos estão explicitadas na Tabela 1.

Tabela 1 - Características do modelo pedagógico e andragógico.

\begin{tabular}{lll}
\hline & Pedagógico & Andragógico \\
Relação professor/aluno & Professor é o centro & Mais centrada no aluno \\
Experiência & Importa a experiência do professor & Experiência do aluno como recurso \\
Vontade de aprender & $\begin{array}{l}\text { Finalidade na obtenção de progressão } \\
\text { escolar }\end{array}$ & $\begin{array}{l}\text { Utilidade para enfrentar } \\
\text { reais }\end{array}$ \\
Orientação da aprenlemas & Resolução de problemas e tarefas \\
Razões da aprendizagem centrada nos conteúdos & Atender a sociedade & Aplicação na prática da vida diária \\
Motivação & Classificações e apreciações externas & Fatores de origem interna \\
\hline
\end{tabular}

Fonte: adaptado de Serguey (1988). 
Neste sentido, torna-se necessário compreender que aprendizagem do adulto permite remeter-se ao desafio da mudança de postura profissional de "professor" para "facilitador". Como enfatizam Silva e Torres (2017), o objetivo deve ser em motivaro aluno a aprender, estimulando-o a debater os conceitos e descobrir novas possibilidades adequadas à sua realidade. Contudo, existe a diferença entre ser um "facilitador" de aprendizagem e um "professor"

Todavia, Lackéus (2018), enfatiza que o facilitador precisa entender a andragogia como um conjunto de princípios de aprendizagem aplicáveis a diversas situações, objetivos, contextos e a pessoas de qualquer idade. O trabalho com o modelo andragógico pode ser considerado uma "arte" vinculada a muitas ciências como biologia, psicologia clínica, sociologia, psicologia social, administração entre outras (Carvalho, 2016).

\subsection{Metodologias ativas como forma de promover a educação empreendedora}

Muitos dos desafios de educadores de diferentes áreas do conhecimento estão pautados em encontrar diferentes metodologias que realmente possam contribuir para a melhoria da eficácia da aprendizagem adulta. Inúmeras formas de aprendizagem têm se apresentado no contexto atual de sociedade, mas é preciso compreender as individualidades e diversidades que compõem a nossa sociedade (Charity et al., 2017). Desta forma, a educação, de modo geral, vem sofrendo mudanças gradativas com o passar dos anos, principalmente relacionadas ao avanço da tecnologia, que por sua vez instiga o sistema de ensino vigente a se adaptar aos recursos provenientes dessa transformação tecnológica.

Silva e Torres (2017), apontam que um processo de ensino-aprendizagem que pressuponha a bagagem cultural do discente, no qual torna-se necessário levar em consideração as competências de cada aluno, de forma a propiciar a melhor forma de aprendizagem. $\mathrm{O}$ aperfeiçoamento de metodologias de aprendizagem no ensino superior, conforme relata Godoi e Ferreira (2016), tem mobilizado grande número de pesquisadores em diferentes áreas do conhecimento na busca pela excelência da docência. Assim, a andragogia, conforme relatado anteriormente, ganha corpo na literatura de educação estando presente em algumas metodologias ativas de aprendizagem como forma de promover a educação empreendedora além de atuar como uma alternativa às metodologias tradicionais.

Torna importante salientar que as metodologias ativas de aprendizagem têm se destacado com uma das formas de promover no discente uma postura empreendedora e ativa em sala de aula em variadas áreas do conhecimento, promovendo uma educação empreendedora, aquela que prioriza a emancipação do aluno inspirando-o às habilidades e atitudes que o fazem praticar o ato de transformar uma realidade (Shepherd, 2011).

Contrapondo-se aos métodos tradicionais de aulas expositivas, os métodos ativos de aprendizagem apresentam-se convidativos aos educadores para transformar alunos passivos em alunos empreendedores durante o processo ensinoaprendizagem. Como afirmam Dalfovo et al., (2017, p. 137):

[...] “a contribuição do educando no processo de ensino é tão relevante quanto o papel do educador, independente de como este conhecimento está sendo abordado, pois como já foi dito, o papel do professor é mediar o ensino e não somente transmiti-lo. Quando o professor consegue captar o estilo de aprendizagem, característico do aluno, a assimilação do conteúdo parece acontecer de forma mais natural, mas na verdade, isto ocorre pelo simples fato de que o conteúdo está sendo apresentado de uma forma mais atrativa ao aluno".

Conforme destaca Bolzan (2017), o aluno contemporâneo diante das competências éticas, políticas e técnicas exigidas, deve ser capaz de auto gerenciar o seu processo de formação. É neste contexto que as metodologias ativas de aprendizagem podem conduzir à busca pela educação de forma empreendedora do discente e ao autogerenciamento e corresponsabilidade pelo seu próprio processo de formação. 
As metodologias ativas, enquanto processo de aprendizagem, incluem o discente de forma ativa no ambiente relacionado à sua profissão, ainda na sua formação, estimulando o estudante a buscar respostas de diversos problemas, possibilitando que se coloque em prática, já na graduação, sua capacidade de exame, reflexão, além de proporcionar meios que o leve à produção de novas pesquisas (Clayton et al., 2017). Assim, por meio de situações reais, ou não, os discentes são capazes de resolver os desafios advindos do ambiente social em diferentes contextos por meio dos problemas apresentados (Bolzan, 2017).

De acordo com Carvalho (2016), a principal diferença entre um ambiente tradicional de ensino para um de aprendizagem ativa é justamente a atitude ativa de pensar, aquela que está atrelada ao empreendimento do aluno em contraste com a atitude passiva, aquela que é associada a métodos tradicionais de ensino. Bolzan (2017), destaca que a capacitação dos docentes com novos métodos de aprendizagem não deve acontecer através de decretos regulatórios e, frequentemente, não trazem os resultados esperados se o objetivo é pautado apenas o currículo de formação.

No entanto, frente à demanda por competências profissionais especificamente do administrador, ressalta-se que é responsabilidade dos gestores da educação superior assumir este compromisso de transição paradigmática do ensino meramente teórico/expositivo para o ensino ativo, moldando a dinâmica educacional em Instituições de Ensino Superior (Charity et al., 2017). Neste sentido, metodologias ativas como a SR surgem como importantes meios para promover uma aprendizagem empreendedora e ativa.

\subsubsection{Simulação Realística como metodologia ativa para a educação empreendedora}

$\mathrm{Na}$ busca por novas metodologias ativas de ensino, especificamente nos cursos de administração, a SR ou simulação de alta fidelidade representa uma promissora possibilidade para formar administradores mais críticos, reflexivos e preparados para a atuação real (Meyer \& Jongh, 2018). A percepção do potencial de tal técnica de ensino vigora em diversas áreas, como no treinamento de pilotos no setor da aviação e, especialmente, no treinamento de profissionais da área da saúde (Gaba, 2007).

No entanto, somente a partir de 1999, que a SR ganhou maior destaque. O relatório do Institute of Medicine, "To Error is Human", em 1999, apresentou dados alarmantes sobre a segurança do paciente mostrando que cerca de 98.000 pacientes morrem por erros durante a hospitalização nos Estados Unidos, anualmente. O relatório aponta falhas de comunicação e trabalho em equipe como causas de muitos erros e traz recomendações sobre programas de treinamento para equipe interdisciplinar com a incorporação da SR como método (Fabri 2017).

É importante destacar que a SR evoluiu e atualmente engloba não somente as habilidades técnicas, mas o gerenciamento de crises, liderança, trabalho em equipe, raciocínio em situações críticas (Clayton et al., 2017). Conforme observam autores como Leonello et. al. (2017), a adoção da SR como nova tecnologia educacional consiste em um importante mecanismo facilitador do processo ensino-aprendizagem, pois oferece novas possibilidades para a ampliação da teoria e da prática para o corpo discente.

Segundo Gaba (2007), a SR pode ser entendida como o processo educacional que replica cenários em um ambiente próximo a realidade, com o objetivo de analisar e refletir as ações realizadas de forma segura. Outra definição proposta pelo autor descreve a simulação como uma técnica que constrói aspectos do mundo real e em ambiente interativo, simula situações que exigem a ação imediata do estudante, colocando-o sob pressão e trazendo a necessidade do exercício de suas softskills e hardskills.

Ypinazar e Margolis (2006), definem a SR como uma metodologia que reproduz situações reais permitindo ao aluno um papel ativo na aquisição dos conceitos necessários para a compreensão e resolução do problema, enquanto que o professor adota uma postura de condutor ou facilitador. Logo, a SR é retratada como uma ferramenta poderosa de aprendizado que pode 
ser aplicada em todos os níveis da educação, enfatizando a multidisciplinaridade em diversas situações cotidianas conforme demonstra a Figura 1.

Figura 1 - Componentes da fidelidade da simulação realística.

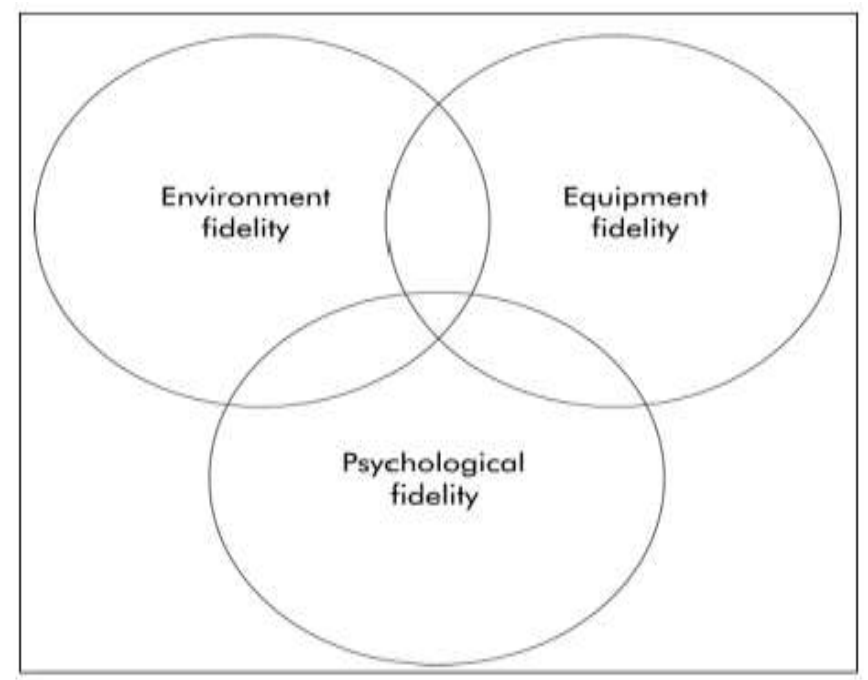

Fonte: Adaptado de Rehmann et al., (1995).

Percebe-se que a SR é uma abordagem que proporciona uma aprendizagem ativa e experiencial (Fabri, 2017). À medida que o aprendizado é consolidado, o foco no conhecimento diminui, passando para competências essenciais e de apoio, a fim de lograr desafios cada vez mais complexos, apresentados ao aprendiz mais experiente (Clayton et al., 2017).

A efetividade da SR, segundo Leonello et. al., (2017), é revelada como tecna de ensino que facilita a aprendizagem quando utilizada sob condições adequadas, ou seja, em um ambiente que permita o desenvolvimento eficaz do método. Contudo, na perspectiva dos professores a simulação contribui com o trabalho em sala de aula, com o processo de aprendizagem do estudante e com a prática docente.

\subsection{Dados sobre o ensino de administração no Brasil e o curso de administração da UFV}

O aumento do número de alunos matriculados nos cursos superiores de Administração vem crescendo a cada dia, configurando-o como o curso com maior número de matriculados do Brasil. De acordo com os dados do Censo da Educação Superior/2015, divulgados em outubro de 2016 pelo Instituto Nacional de Estudos e Pesquisas Educacionais Anísio Teixeira INEP e pelo Conselho Federal de Administração - CFA, o curso de bacharelado em administração é um dos mais ofertados do país, possuindo um total de 793.564 matrículas, quantitativo que representa $12 \%$ do universo de estudantes regularmente matriculados no ensino superior. Além dos cursos de bacharelado em administração, destaca-se um quantitativo de 512.007 matrículas em cursos superiores de tecnologia em administração no Brasil, o que representa $8 \%$ do total de alunos matriculados em instituição de ensino superior (INEP, 2017; CFA, 2017). Em 1995, o número de alunos matriculados era de 195.287 e, em 2015 (última disponibilização dos dados do Censo do Ensino Superior), 1.330.483 alunos estavam matriculados (Bolzan, 2017).

Sabe-se que fatores de competitividade almejados pelos indivíduos ainda em formação ou já nos programas de pósgraduação em administração, centrados na empregabilidade, flexibilidade, inovação, capacidade adaptativa, resiliência, dentre outros, colocam como recorrente o questionamento, sobre a capacidade de os atuais processos de formação efetivamente fomentarem o desenvolvimento e mobilização de tais atributos de competência, em particular, face aos modelos mais 
tradicionais de ensino vigentes em ampla gama de cursos de graduação - e mesmo pós-graduação - em Administração (Barcellos et. al., 2011).

O curso de administração da UFV, criado em 1976, teve seu reconhecimento em 21/01/1980 pela Portaria do MEC N $^{\circ}$ 91. Nele, a atuação esperada do profissional de administração é que o mesmo seja capacitado a gerir recursos de toda a ordem, mediante o exercício do planejamento, da organização, da direção e do controle, no âmbito das organizações de qualquer natureza ou porte, com vistas à otimização do processo de tomada de decisão, facilitando a resolução de problemas e a vivência organizacional como fatores preponderantes na maximização de resultados (Bolzan, 2017). Sabe-se que o administrador pode assumir papéis diferenciados - assessores, executivo, pesquisador, consultor, empreendedor e, ou, professor - em áreas como finanças, mercadologia, operações, logística, estratégia, gestão de pessoas e administração geral (Godoi \& Ferreira, 2016).

No sentido de atender a esta gama diversificada de atuação do administrador, a matriz curricular do curso de Administração/UFV encontra-se estruturada num modelo em que o estudante inicialmente tem contato com as disciplinas básicas e posteriormente cursa disciplinas profissionalizantes, numa sequência pré-definida para as disciplinas obrigatórias. Há flexibilidade para selecionar as disciplinas optativas, no decorrer do curso, finalizando com a realização de estágio supervisionado (Bolzan, 2017).

Nesse contexto, vislumbra-se a necessidade de buscar práticas educacionais que favoreçam a ampliação do pensamento crítico do estudante de administração, possibilitando sua integração com o ambiente profissional já nos semestres iniciais do curso (Penaluna, 2018). Assim, a relevância deste estudo consiste em propiciar elementos que venham a constatar em que extensão a SR apresenta-se de forma significativa no desenvolvimento de competências profissionais e na educação empreendedora que são requeridas pelas organizações contemporâneas.

\section{Percurso Metodológico}

Nesta sessão serão apresentados os procedimentos metodológicos da pesquisa. A sessão se divide em quatro tópicos: Caracterização metodológicas e sujeitos da pesquisa; Instrumento de coleta de dados; Estratégias para coleta de dados e; Tratamento e análise dos dados. Estes tópicos têm o objetivo de demonstrar de forma sistematizada o percurso metodológico utilizado para alcançar os principais achados da pesquisa.

\subsection{Características metodológicas e sujeitos de Pesquisa}

Este estudo pode ser caracterizado como de abordagem qualitativa, desenvolvido segundo o método de estudo de caso único, pois observou apenas a UFV como instituição de ensino na prática de educação empreendedora, tendo por base a adoção da metodologia de SR visando proporcionar aos sujeitos de investigação uma experiência próxima da realidade, seguida de entrevistas semiestruturadas.

O estudo foi realizado com alunos da graduação em administração e alunos do programa de mestrado também em administração da UFV. O Departamento de Administração da UFV foi escolhido para este estudo pelo seu histórico em atuar com excelência no atendimento e na promoção do bem-estar e das aspirações sociais, mediante processo integrado de ensino pesquisa e extensão para melhor formação de profissionais. Ademais, existe grande preocupação da instituição em repensar a matriz curricular para melhor alinhar as necessidades do mercado com a formação de seus respectivos alunos. Portanto, configura-se como campo de pesquisa adequado para o presente trabalho. 
O cenário simulado foi realizado no prédio da Coordenadoria de Educação Aberta e a Distância - CEAD, da UFV. O CEAD foi utilizado por possuir capacidade já instalada tanto para trazer realismo ao ambiente de simulação escolhido, quanto para captação e transmissão de áudio e imagem para sala de observação.

O universo estudado foi composto por dois grupos de trabalho, sendo cinco estudantes da graduação em Administração e sete do programa de mestrado em Administração do Departamento de Administração da UFV. Esta unidade de estudo foi escolhida por conveniência, ou seja, o trabalho foi executado com alunos voluntários. A utilização de uma amostragem não probabilística exige retirar a amostra de uma parcela acessível da população.

Aos integrantes de ambos os grupos foi livremente solicitado a comparecer no dia da simulação pelo professor do departamento da administração. O grupo da graduação ficou composto por um estudante do terceiro período, um do quinto, dois do sétimo e um do oitavo. O grupo dos integrantes do mestrado, composto por alunos em fase de conclusão da etapa de disciplinas, constituiu-se por quatro alunos com graduação prévia em administração, dois com formação básica em ciências contábeis e outro com formação em agronegócio. Todas as graduações foram concluídas na mesma instituição do programa.

Cabe salientar a solicitação a cada estudante de consentimento livre e esclarecido para participar do estudo, garantindo-se a confidencialidade das informações e seu anonimato. Um exemplo de roteiro para auxiliar a implementação da SR foi apresentado por Fabri (2017), com foco nos profissionais de saúde. Este modelo teórico prático foi construído com o propósito de instrumentalizar a atividade do professor/facilitador na aplicação da SR e resultou em sete unidades de significância: 1. Conhecimento prévio do aprendiz, 2. Objetivos da aprendizagem, 3. Fundamentação teórica, 4. Preparo do cenário, 5. Desenvolvimento do cenário, 6. Debriefing e 7. Avaliação.

As SR executada foi um processo de demissão. Criou-se um roteiro com o enredo que levou a demissão de uma técnica em enfermagem, onde o cenário simulava o processo de gestão de um hospital particular. A partir de um erro médico e de complicações aos pacientes que resultaram em processos ao hospital e avaliação de responsabilidades o conselho de administração atribuiu a técnica em enfermagem a responsabilidade. Cabia ao aluno, compreender o processo, o enredo, e promover a demissão. A SR pede o cenário onde esse enredo seja construído, tenha "atores" com claridade do papel, seja realizado em ambiente cuja interação aconteça apenas entre os participantes diretor do processo de demissão, e seja transmitido para um grupo de observadores. Posteriormente se promove o debate.

\subsection{Instrumento de coleta de dados}

Após a simulação do processo os participantes foram estimulados a narrar livremente sobre as experiências vivenciadas junto à metodologia de SR. O aluno selecionado foi incumbido de realizar a demissão da funcionária frente a esta profissional que estava orientada a debater a decisão, vivenciando uma situação atípica de um administrador/gestor. As respostas não foram condicionadas a uma padronização (Fabri, 2017). No entanto, o entrevistador utilizou-se de um roteiro prévio com tópicos que deveriam ser contemplados na entrevista. As questões tiveram origem a partir do problema de pesquisa e buscaram tratar o tema central de uma maneira ampla. O principal objetivo do roteiro foi fomentar a coleta de informações básicas e organizar a interação entre entrevistador e entrevistado.

\subsection{Estratégias para coleta de dados}

Para a coleta de dados fez-se uso de instrumentos múltiplos. Além de entrevistas o estudo utilizou-se de observação direta e grupos focais envolvendo os participantes. Cabe registrar que cada participante foi entrevistado separadamente e todas as entrevistas foram gravadas. O modelo de entrevista em profundidade é consolidado como um dos caminhos eficazes para compreender e descrever os fenômenos observados. Favorece a investigação e a captação da percepção dos participantes frente a situação vivenciada (Gaba 2007). 


\subsection{Tratamento e análise dos dados}

Para análise dos dados coletados por meio de entrevistas empregou-se o método de análise de conteúdo por categoria, conforme critérios delineados por Bardin (2014). Segundo o autor, a técnica prioriza a sistematização, interpretação e descrição do conteúdo das informações coletadas, com objetivo de entender o discurso, aprofundar em suas características e extrair os detalhes mais importantes (Bardin, 2014). Para isso, buscou-se, identificar no processo pontos comuns e pontos de divergência em relação à metodologia da SR como caminho para educação empreendedora no curso de administração de maneira a comparar os grupos estudados para alcançar os resultados.

\section{Resultados e Discussão}

Destaca-se que os alunos da graduação, com exceção de um, estavam todos nos dois últimos anos do curso. Enquanto, todos os alunos do mestrado, haviam iniciado o programa há seis meses. O ambiente acadêmico frequentado por todos os participantes foi apenas a UFV, mesmo do grupo do mestrado, todos cursaram suas graduações na instituição.

Do total de graduandos e mestrando participantes deste estudo, nota-se a partir dos relatos que a maioria não tinha vivenciado em suas respectivas rotinas de sala de aula alguma metodologia ativa de ensino desta natureza. Entretanto, por meio dos grupos de foco, do compartilhamento, da criação de uma atmosfera de liberdade, foi possível construir uma participação efetiva de todos os envolvidos.

Apesar de o cenário simulado ter sido o mesmo, cada grupo desenvolveu, durante o debriefing, uma discussão de forma distinta. Assim, por meio da problematização e resgate da cena do processo de demissão, estimulou-se a reflexão sobre os principais acontecimentos da simulação, permitindo a mobilização dos domínios cognitivo e afetivo para lidar com uma situação complexa, facilitando a utilização do conhecimento na vida profissional futura dos alunos (Godo \& Ferreira, 2016).

No início de cada entrevista, cada participante teve oportunidade de expressar livremente suas percepções em relação à experiência como um todo. Todos gostaram muito da simulação e apontaram em suas considerações como "interessante", "inovador", "melhora a experiência como aluno", além de "estimular raciocínio" e ter "potencial para preencher a lacuna teoria-prática" apontada por todos como presente nos programas de administração.

Entre os graduandos, "capacidade de envolver pessoas/trabalhar em equipe" apareceu em três respostas dos participantes, seguida por "liderança" em duas ocasiões. Na sequência apontaram oportunidade de mais prática, tomada de decisão, entendimento econômico, empreendedorismo, resiliência, empatia, capacidade crítica como importante na formação dos administradores. Entre os mestrandos, "lidar com pessoas" ganhou destaque em três respostas, seguida de "liderança", "visão mais holística", "conhecimento básico" e "comunicação".

Em relação ao que efetivamente a metodologia permitiu desenvolver, o grupo da graduação se mostrou mais impactado ao perceber suas respectivas necessidades de ter postura enérgica frente aos problemas a serem enfrentados e ficou explícito na resposta de dois alunos quanto a possibilidade de a simulação melhorar o modo de se comunicar ou expressar (Charity, et. al., 2017). Apesar das falas não serem exatamente iguais entre os grupos as percepções do que consideram importante na formação do administrador e o que a metodologia permitiu desenvolver estão bem alinhadas a suas próprias expectativas.

Assim, sobre a contribuição em potencial da metodologia, ficou evidenciado uma visão positiva sobre a experiência como caminho possível para a materialização de vivência em situações práticas e de pressão, ponto este, recorrente em todas as entrevistas identificando assim como esta metodologia ativa pode influenciar na educação empreendedora dos alunos de administração.

A SR vivenciada pelos participantes dos dois casos mostrou-se como experiência inovadora para a grande maioria. 
Em ambos os casos os participantes, tanto da graduação quanto do mestrado, consideraram que a adoção da metodologia da simulação pela instituição (UFV) seria favorável para o processo ensino-aprendizagem. Estes resultados são similares ao estudo de Leonello et al. (2017), que recomendam a inclusão da simulação como estratégia de ensino, devido a seu potencial para estimular a aprendizagem colaborativa e o desenvolvimento do pensamento crítico, voltados para o autoconhecimento e a melhoria do desempenho no âmbito profissional. Quanto às fragilidades do cenário executado, a maioria dos participantes (7), considerados os graduandos e mestrandos, não destacaram qualquer ponto negativo.

Finalmente, sobre o debriefing, a fase de debate a pós a realização e observação, todos foram unânimes em apontá-lo como a fase mais válida, enriquecedora e inclusiva. Um integrante do mestrado sugeriu a participação de mais facilitadores em uma próxima oportunidade. A plena integração do grupo é objetivo primordial desta etapa na qual o discente pode discutir livremente os acontecimentos vivenciados ou observados instantes antes. Inclusive, o debriefing é realizado imediatamente após a simulação para explorar e ajudar a sedimentar o aprendizado. Isto presta-se tanto a catalisar o aprendizado quanto permite refletir sobre os pontos a serem melhorados (Bolzan, 2017).

Os achados do presente estudo corroboram com a pesquisa realizada por Carvalho (2016), onde se destaca que a simulação é uma metodologia dinâmica e promove integração do grande grupo, principalmente, no momento do debriefing. É nesta etapa que todos os discentes podem discutir sobre a cena vivenciada. Corroboram também com este pensamento e com os resultados do nosso estudo, os autores Godoi e Ferreira (2016), que afirmam que debriefing é fornecido imediatamente após a SR e ele tem o objetivo de ajudar a consolidar a aprendizagem dos alunos. Neste sentido, facilita tanto a aprendizagem quanto possibilita a reflexão dos discentes sobre identificar áreas de que estes podem melhorar.

Foi oportunizado aos participantes explicitarem de maneira mais direta suas percepções sobre a possível contribuição da metodologia adotada no sentido de alcançar desenvolvimento de raciocínio, solução de problemas, tomada de decisão, abordagem holística, comunicação efetiva, liderança e emoções. Entre todos os participantes, as respostas foram positivas, variando um pouco a ênfase dada em cada item, mas concordantes.

No mais, a SR coloca os alunos frente situações problemas típicas da prática profissional, demandam mobilização de saberes anteriormente adquiridos e estimula o raciocínio crítico (Shepherd, 2011). A satisfação dos discentes quanto à metodologia foi grande e, nota-se poucas divergências entre os dois grupos estudados, apesar da heterogeneidade dos entrevistados.

Nesse sentido, corroborando os resultados deste estudo, Dalfovo, et. al. (2017) reflete sobre as metodologias ativas e a simulação realística no processo de ensino aprendizagem numa perspectiva de construção de saberes em que alunos e professores participam efetivamente e, implica em substituir os processos de memorização de informações e de transferência fragmentada do saber de forma vertical.

A visão dos participantes sobre a formação futura do administrador de forma empreendedora trouxe percepções diferentes, mas não divergentes, entre os mestrandos e graduandos. Os estudantes de graduação, de modo unânime, apontam a utilização da simulação como um caminho para aproximação da prática e promoção de uma educação empreendedora com a teoria e pautam a discussão sobre a necessidade da utilização de metodologias ativas como a simulação realística no sentido de contribuir para o desenvolvimento de lideranças, atitudes empreendedoras, e também para o aspecto humano e profissional, focando também na necessidade de maior vivência prática.

Já os estudantes de mestrado consideram que além da necessidade de mais prática, é preciso que o ensino em administração possa ter uma visão mais holística do ser humano para que se discuta também o "ser” comportamental. Também mencionam que a administração vem perdendo espaço para outras áreas e precisa evoluir no sentido de incorporar áreas que atualmente não fazem parte do currículo do administrador, mas que poderiam contribuir para uma formação mais dinâmica, menos teórica e mais próxima das demandas do mercado de trabalho, ou seja, uma educação empreendedora. 


\section{Conclusão}

Cabe às instituições de ensino a árdua tarefa de responder às demandas da sociedade no que se refere ao mercado de trabalho. As universidades almejam fornecer profissionais alinhados com as demandas do mercado, capazes de atingir a real necessidade vigente. Isso envolve construir um perfil profissional com peculiaridades de internacionalização, manejo de novas tecnologias, visão holística e aprendizado para a vida.

Além disso, percebe-se que as recomendações pedagógicas se alinham para conferir novas diretrizes ao sistema de educação que conduzam os estudantes ao desenvolvimento de competências ligadas ao profissionalismo. Assim, revisar os processos de ensino e aprendizagem é vital no intuito de se elaborar um novo formato de modelo didático condizente com a vida real e focado na formação de profissionais.

Nesse sentido, ganha destaque o uso de metodologias ativas como instrumento pedagógico no processo de educação empreendedora como possível caminho para o desenvolvimento profissional dos estudantes. São metodologias inovadoras com ênfase no processo de ensino, aprendizagem e avaliação ao colocarem o aluno como protagonista, agentes proativos, motivados a buscar com liberdade e autonomia a solução para problemas reais e complexos. Assim, é necessário rever o papel das instituições de ensino a partir de ações coletivas e diretrizes políticas.

No presente estudo, a ênfase recai sobre os cursos de administração, área reconhecidamente estratégica para o desenvolvimento sustentável de qualquer nação. E em relação, especificamente à SR, onde a percepção do grupo participante foi amplamente positiva em vários sentidos. Nesta direção, destaca-se que um dos grandes potenciais da SR é em envolver seus participantes na resolução de problemas e na reflexão mais aprofundada sobre situações reais promovendo assim uma educação empreendedora a estes alunos.

Os participantes também reconhecem o potencial para possíveis aplicações da metodologia de forma a atender outras disciplinas da administração. Apresenta-se recorrente a crítica ao atual modelo de ensino no que tange ao distanciamento da prática. Inclusive, alinhada a visão de futuro dos participantes, a SR é percebida como possibilidade para preencher essa lacuna.

Por outro lado, como já anteriormente mencionado, registram-se poucas divergências em relação às respostas entre os dois grupos estudados apesar da heterogeneidade dos entrevistados. Uma provável explicação reside no fato de todos os participantes terem estudado na mesma instituição e praticamente terem pouco tempo de mercado de trabalho. Mesmo os mestrandos, optaram por ingressar no programa logo após o final da graduação.

Outro ponto relevante constatado que merece ser mencionado constitui a ausência prévia por parte dos participantes de experiências com metodologia ativas de ensino. Por fim, ao que se refere a trabalhos acadêmicos prévios na área de administração sobre simulação realística, nota-se uma ausência completa de trabalho nos bancos de dados pesquisados.

Contudo, o parecer dos envolvidos foi recomendar a metodologia ativa de SR como modelo pedagógico viável em programas de formação de administradores como forma de promover uma educação mais ativa e empreendedora. Pelos achados do trabalho, pode-se inferir a possibilidade de êxito na elaboração e implementação de um desenho de ensino críticoreflexivo calcado em metodologias ativas.

Ressalta-se que o presente artigo não teve a finalidade de esgotar as possibilidades analíticas de aplicação de metodologias ativas como meio de promover a educação empreendedora. Novos estudos precisam ser desenvolvidos e divulgados para fomentar a promoção de uma educação empreendedora nos cursos de administração.

Deste modo, para trabalhos futuros, sugere-se a realização de: Estudos comparativos da simulação realística com outras metodologias ativas para verificar a retenção de conhecimento e desenvolvimento de competências na promoção da educação empreendedora e estudos que possibilitem o desenvolvimento de instrumentos que facilitem a avaliação e 
monitorização do impacto das mudanças introduzidas pela SR.

\section{Agradecimentos}

Ao Centro de Referência em Empreendedorismo e Cooperativismo - CREC-UFV, ao Departamento de Administração da Universidade Federal de Viçosa - DAD-UFV, ao Centro Universitário Unifaminas e a Coordenação de Aperfeiçoamento de Pessoal de Nível Superior- CAPES.

\section{Referências}

Barcellos, R. M. R., Dellagnelo, E. H. L. \& Saliés, G. P. (2011). Universidade, sociedade e formação do administrador: uma reflexão necessária. Administração: Ensino e Pesquisa. 12(4), 671-96.

Bardin, L (2014). Análise de Conteúdo: Edições 70.

Bolzan, L. M. (2017). Processos de ensino, de aprendizagem e de avaliação nos cursos superiores de administração sob a percepção de professores e de estudantes. Escola de Administração, Universidade Federal do Rio Grande do Sul.

Carvalho, J. R. (2016). Andragogia: saberes docentes na educação de adultos. Revista Diálogos Acadêmicos (Fortaleza).

Charity, D., Ozoji, B. E., Osasebor, F. O., \& Umar, S. I. (2017). Effects of Teaching Gardening on Science Students Attitudes toward Entrepreneurial Skills Acquisition in Jos South, Plateau State, Nigeria. Rev. Science Education International, International Council of Associations for Science Education, Hatfield [Inglaterra]. 28(2), 136-140.

Clayton, M. F., Supiano, K., Wilson, R., Lassche, M, \& Latendresse, G. (2017). Using simulation in nursing PhD education: facilitating application of responsible conduct of research principles. J Prof Nurs; 33(1):68-73.

Conselho Federal de Administração (2018). Censo do curso de administração. https://www.cfa.org.br/servicos/formacao-profissional/censo-dos-cursos-debacharelado-em--admnistracao-e-dos-cursos-superiores-de-tecnologia-nas-diversas-areas-da-administracao.

Dalfovo, M. S., Machado, M. M., Dalfovo, O., \& Aldrovandi, M. A. (2017). Análise da relação dos estilos de aprendizagem na percepção do método de ensino. Rev Adm e Negócios da Amazônia; 9(3):116-138.

Deveci, I., \& Çepni, S. (2017). Studies conducted on Entrepreneuship in Science Education: thematic review of research. Jornal of Turkish Science Education. Ekip Limited, 14, 126-141.

Fabri, R. P., Mazzo, A., Martins, J. C. A., Fonseca, A. S., Pedersoli, C. E., \& Miranda, F. B. G. (2017). Development of a theoretical-practical script for clinical simulation. Rev Esc Enferm USP. 51:e03218.

Gaba, D. M. (2007). The future vision of simulation in healthcare. Simul Healthc; 2(2):126-35.

Godoi, A. F., \& Ferreira, J. V. (2016). Metodologia ativa de aprendizagem para o ensino em administração: relatos da experiência com a aplicação do peer instruction em uma instituição de ensino superior. Rev Eletrônica de Administração. 15(2).

International Nursing Association For Clinical Simulation And Learning - US (2016). Standards Committee. INACSL Standards Committee. INACSL Standards of best practice: Simulation-enhanced interprofessional education (Sim-IPE). Clin Simul Nurs. (Suppl): S34-S38. https://doi.org/10.1016/j.ecns.2016.09.011. 2016.

Lackéus, M. (2018). Entrepreneurship in education: what, why, when, how. Paris: Organisation for Economic Co-operation and Development, European Commission, 2015. https://www.oecd.org/cfe/leed/BGP .

Leonello, V. M., Leite, M. M. J., Almeida, D. M., \& Dias, C. A. (2017). Simulação como estratégia para o ensino. Rev Grad (USP).

Meyer, N., Jongh, J. (2018). The importance of entrepreneurship as a contributing factor to economic growth and development: the case of selected European countries. Journal of Economics and Behavioral Studies. 10(4), 287-299.

Neck, H. M., Neck, C. P., \& Murray, E. L. (2018). Entrepreneurship: the practice and mindset. Los Angeles: Journal, SAGE.

Penaluna, A. (2018). Enterprise and Entrepreneurship Education: Guidance for UK Higher Education Providers. Gloucester: The Quality Assurance Agency for Higher Education.

Rehmann, A., Mitman, R., \& Reynolds, M. A. (1995). Handbook off flight simulation fidelity requirements for human factors research. Technical report No. DOT/FAA/CTTN95/46. Xenia, OH: Crew Systems Ergonomics Information Analysis Centre, Wright-Patterson Air Force Base.

Romanowski, J. P. (2007). Formação e profissionalização docente. (3a ed.): Ibpex.

Shepherd, D. A., \& Patzelt, H. (2011). The New Field of Sustainable Entrepreneurship: Studying Entrepreneurial Action Linking, What Is to Be Sustained, With What Is to Be Developed? Entrepreneurship Theory and Practice.

Serguey, I. Z. (1998). Andragogy: origins, developments and trends. Journal of lifelong education. 44(1):103-108. 
Research, Society and Development, v. 10, n. 3, e9610313066, 2021

(CC BY 4.0) | ISSN 2525-3409 | DOI: http://dx.doi.org/10.33448/rsd-v10i3.13066

Silva, M. L. C. A., \& Torres, M. L. (2017). O estado da arte em andragogia: uma análise nas produções científicas. Acta Científica (Engenheiro Coelho). 4354. https://dx.doi.org/10.19141/2236-2622/actacientifica.v26.n2.p43-54. 2017.

WEF. New vision for Education: Unlocking the Potential of Technology. https://www3.weforum.org/docs/WEFUSA_N ewVisionforEduca tion_Report2015.pdf.2016.

Ypinazar, V. A., \& Margolis, S. S. (2006). Clinical simulators: applications and implications for rural medical education. Rural Remote Health. 6(2):527. 2006. 